\title{
ANALISIS PENGARUH SANITASI DAN ANGKA KEMATIAN IBU TERHADAP INDEKS PEMBANGUNAN MANUSIA DI SUMATERA UTARA
}

\author{
Natasya Santa Elisabeth Siahaan \\ Fakultas Ekonomi dan Bisnis Universitas Sumatera Utara \\ Email: kiezkey_1809@yahoo.com
}

\begin{abstract}
This study aims to determine the Inadequate Sanitation Influence and Maternal Mortality Rate on Human Development Index (HDI) in North Sumatra. The analytical tool used in this study is the Panel Regression Analysis through the Panel Least Square (PLS) method using the Eviews 10. program. The data used is a panel data consisting of 33 districts and cities in North Sumatra from 2014 to 2016. The result shows that improper sanitation and maternal mortality have a negative and significant effect on the human development index in North Sumatra. While simultaneously, improper sanitation and maternal mortality rates have a significant effect on the human development index in North Sumatra.
\end{abstract}

Key words: Inadequate Sanitation, Maternal Mortality Rate, HDI, North Sumatera

\section{PENDAHULUAN}

P

embangunan kesehatan harus dilakukan dengan pendekatan komprehensif, dengan mengacu pada visi misi Presiden. Upaya untuk mewujudkan visi ini dilakukan melalui 7 misi pembangunan, dimana pada misi ke-4 adalah mewujudkan kualitas hidup manusia lndonesia yang tinggi, maju dan sejahtera. Dalam pembangunan nasional 2015-2019 juga dibangun kemandirian di bidang ekonomi, berdaulat di bidang politik dan berkepribadian dalam budaya yang dikenal dengan Trisakti. Untuk mewujudkannya, ditetapkan 9 agenda prioritas (Nawacita), dimana pada agenda ke-5 dimaksudkan untuk meningkatkan kualitas hidup manusia Indonesia yang akan dicapai melalui Program Indonesia Pintar, Program Indonesia Sehat dan Program Indonesia Kerja Indonesia sejahtera (Dinas Kesehatan Kota Medan, 2016). Program Indonesia sehat memiliki 3 komponen yaitu: 1) Revolusi mental masyarakat agar memiliki paradigma sehat; 2) Penguatan Pelayanan Kesehatan; dan 3) Mewujudkan Jaminan Kesehatan Nasional (JKN). Semangat membangun dari pinggiran tercermin dalam upaya penguatan

$$
\text { QE Journal |Vol.07 - No. } 02 \text { July } 2018 \text { - } 116
$$


pelayanan kesehatan di daerah terpencil, perbatasan, dan kepulauan (DTPK), Kemenkes memiliki terobosan untuk menempatkan tenaga kesehatan secara tim yang kita namakan program Nusantara Sehat (NS). Sedangkan penguatan upaya kesehatan berbasis masyarakat melalui pendekatan keluarga juga terus diupayakan, ini yang disebut program Keluarga Sehat.

Situasi derajat kesehatan dapat dilihat dengan menilai derajat kesehatan masyarakat dengan menggunaan indikator yang mencerminkan kondisi mortalitas (kematian); morbiditas (kesakitan); serta status gizi pada balita dan dewasa. Mortalitas telah disepakati tiga indikator, yaitu Angka Kematian Bayi (AKB) per 1.000 Kelahiran Hidup, Angka Kematian Balita (AKABA) per-1.000 Kelahiran Hidup, dan Angka Kematian Ibu (AKI) per100.000 Kelahiran Hidup. Angka Kematian Ibu (AKI) termasuk salah satu indikator penting dari derajat kesehatan masyarakat.

WHO (2009) melaporkan bahwa air bersih, sanitasi, dan higiene yang buruk masuk dalam the leading global risks for burden of disease. Di negara-negara dengan tingkat pendapatan rendah (low-income countries) air bersih, sanitasi, dan higiene merupakan faktor risiko penyebab penyakit keempat dengan jumlah korban yang meninggal sebanyak 1,6 juta jiwa (6,1 persen). Permasalahan air bersih, sanitasi, dan higiene yang buruk meningkatkan kejadian penyakit diare. Sebagian besar kematian diare di dunia (88 persen) disebabkan oleh air, sanitasi, atau higiene. Secara keseluruhan, hampir seluruh kematian ini terjadi di negara-negara berkembang.

Penelitian lainnya tentang Kematian Ibu dilakukan oleh Aristia (2011) juga menyatakan bahwa persentase rumah tangga berperilaku hidup bersih dan sehat berpengaruh secara signifikan terhadap jumlah kematian ibu. Sejalan dengan penelitian sebelumnya, penelitian yang dilakukan oleh Pertiwi pada tahun 2012 juga menemukan hasil yang sama. Hasil penelitiannya menyatakan bahwa persentase persalinan dibantu oleh dukun, persentase rumah tangga berperilaku hidup bersih sehat, dan persentase sarana kesehatan di tiap kabupaten/kota di Jawa Timur berpengaruh secara signifikan terhadap jumlah kematian ibu.

Sanitasi yang baik memberikan pengaruh sangat signifikan bagi penurunan angka kematian ibu. Oleh karena itu, perlu dikaji mengenai 
Pengaruh Sanitasi terhadap Angka Kematian Ibu dan Indeks Pembangunan Manusia (IPM) di Sumatera Utara.

\section{Konsep Dasar Sanitasi}

Pengertian sanitasi secara umum, sanitasi adalah pencegahan penyakit dengan mengurangi atau mengendalikan faktor - faktor lingkungan fisik yang berhubungan dengan rantai penularan penyakit. Pengertian lain dari sanitasi adalah upaya pencegahan penyakit melalui pengendalian faktor lingkungan yang menjadi mata rantai penularan penyakit.

Sanitasi bertujuan dan fungsi untuk kebersihan secara umum terhadap penyebab yang terletak pada faktor lingkungan. Sanitasi merupakan suatu cara dalam penyediaan air bersih bagi pemakai air di dalam bangunan, dapat berupa air dingin ataukah air panas. Sistem jaringan air bersih tersebut, adalah sistem pemipaan yang dipersiapkan dalam bangunan maupun juga di luar bangunan untuk mengalirkan air bersih dari sumber menuju keluaran. Sistem tersebut memiliki tujuan dan fungsi. Fungsi dan tujuan tersebut guna memenuhi kebutuhan air bersih suatu daerah atau negara khususnya negara Indonesia, dan kemudian didistribusikan kepada konsumen (Darwin, 2014).

Sanitasi Lingkungan adalah status kesehatan suatu lingkungan yang mencakup perumahan, pembuangan kotoran, penyedian air bersih dan sebagainya. Sanitasi lingkungan ditujukan untuk memenuhi persyaratan lingkungan yang sehat dan nyaman. Upaya sanitasi dasar meliputi sarana pembuangan kotoran manusia, sarana pembuangan sampah, saluran pembuangan air limbah, dan penyediaan air bersih. Sarana pembuangan kotoran manusia atau yang biasa disebut jamban harus dimiliki oleh tiap keluarga yang harus selalu terawat atau bersih dan sehat (Ryadi, 2016).

Hal ini untuk mencegah pencemaran lingkungan dari kotoran manusia dan sebagai tanda bahwa keluarga tersebut tidak BAB di sembarang tempat. Sarana pembuangan sampah juga termasuk upaya sanitasi dasar karena setiap manusia pasti meghasilkan sampah. Sanitasi dasar yang selanjutnya yaitu saluran pembuangan air limbah. Saluran ini menampung air bekas dari aktivitas mencuci, masak, mandi dan sebagainya. Saluran pembuangan air limbah menjadi sangat penting bukan hanya karena alasan bau dan estetika tetapi karena air limbah yang berbahaya bagi kesehatan. 
Karena itu, saluran air limbah diusahakan agar tidak mencemari lingkugan sekitar dan tertutup. Upaya sanitasi dasar yang terakhir yaitu penyediaan air bersih. Air bersih merupakan kebutuhan dasar manusia yang harus dipenuhi. Sanitasi dasar dan kualitas bakteriologis air penting untuk dipenuhi untuk menjaga kualitas sanitasi lingkungan yang baik. Jika lingkungan memiliki kualitas sanitasi dan kualitas bakteriologis air bersih yang buruk, maka masyarakat yang tinggal di lingkungan tersebut akan mudah terkena penyakit (Sidhi, 2016).

\section{Konsep Dasar Angka Kematian Ibu}

Angka Kematian Ibu (AKI) mencerminkan risiko yang dihadapi ibu-ibu selama kehamilan dan melahirkan yang dipengaruhi oleh status gizi ibu, keadaan sosial ekonomi, keadaan kesehatan yang kurang baik menjelang kehamilan, kejadian berbagai komplikasi pada kehamilan dan kelahiran, serta penggunaan fasilitas pelayanan kesehatan termasuk pelayanan prenatal dan obstetri. Tingginya angka kematian ibu menunjukkan keadaan sosial ekonomi yang rendah dan fasilitas pelayanan kesehatan termasuk pelayanan prenatal dan obstetri yang rendah pula (Sari, 2016).

Kematian ibu biasanya terjadi karena tidak mempunyai akses ke pelayanan kesehatan ibu yang berkualitas, terutama pelayanan kegawatdaruratan tepat waktu yang dilatarbelakangi oleh terlambat mengenal tanda bahaya dan mengambil keputusan, terlambat mencapai fasilitas kesehatan, serta terlambat mendapatkan pelayanan di fasilitas kesehatan. Selain itu penyebab kematian maternal juga tidak terlepas dari kondisi ibu itu sendiri dan merupakan salah satu dari kriteria 4 "terlalu", yaitu terlalu tua pada saat melahirkan ( $>35$ tahun), terlalu muda pada saat melahirkan $(<20$ tahun), terlalu banyak anak ( $>4$ anak), terlalu rapat jarak kelahiran/paritas $(<2$ tahun).

Berbagai upaya dilakukan untuk menurunkan AKI, Kementerian Kesehatan Republik Indonesia Mencanangkan Making Pregnancy Safer (MPS) dengan optimal. MPS mengharapkan agar ibu hamil, melahirkan dan dalam masa setelah persalinan (post natal) mempunyaai akses terhadap tenaga kesehatan terlatih. Strategi MPS meliputi tiga pesan kunci, yakni:

(1).Setiap persalinan harus ditolong oleh tenaga kesehatan yang memiliki kompetensi kebidanan; (2).Setiap komplikasi persalinan harus ditangani tenaga adekuat (dokter ahli).; (3).Setiap wanita usia subur harus 
mempunyai akses pencegahan kehamilan dan penanganan komplikasi keguguran.

MPS antara lain terimplementasi dalam program Jampersal untuk menjamin semua persalinan dilakukan di fasilitas kesehatan dan oleh tenaga kesehatan terlatih serta penyediaan pelayanan obstetri neonatal emergensi dasar (PONED) dan pelayanan obstetri neonatal emergensi komprehensif (PONEK) untuk menjamin semua komplikasi obstetrik dapat tertangani. Selain itu, Kementerian Negara Pemberdayaan Perempuan juga Mencanangkan Gerakan Sayang Ibu (GSI) sebagai upaya menumbuhkan kesadaran bahwa kehamilan dan kelahiran dapat memunculkan risiko dan tidak hanya menjadi tanggung jawab ibu, tetapi juga juga keluarga, suami, orang tua, dan masyarakat.

\section{Konsep Dasar Indeks Pembangunan Manusia}

UNDP (United Nation Development Programme) mendefenisikan pembangunan manusia sebagai suatu proses untuk memperluas pilihanpilihan bagi penduduk. Dalam konsep tersebut penduduk ditempatkan sebagai tujuan akhir (the ultimated end) sedangkan upaya pembangunan dipandang sebagai sarana (principal means) untuk mencapai tujuan itu. Untuk menjamin tercapainya tujuan pembangunan manusia, empat hal pokok yang perlu diperhatikan adalah produktivitas, pemerataan, kesinambungan, pemberdayaan (UNDP, 1995).

IPM mencakup tiga komponen yang dianggap mendasar bagi manusia dan secara operasional mudah dihitung untuk menghasilkan suatu ukuran yang merefleksikan upaya pembangunan manusia. Ketiga komponen tersebut adalah peluang hidup (longevity), pengetahuan (knowledge) dan hidup layak (living standards).

Peluang hidup dihitung berdasarkan angka harapan hidup ketika lahir; pengetahuan diukur berdasarkan rata-rata lama sekolah dan angka melek huruf penduduk berusia 15 tahun ke atas; dan hidup layak diukur dengan pengeluaran per kapita yang didasarkan pada paritas daya beli (purchasing power parity).

Nilai IPM suatu negara atau wilayah menunjukkan seberapa jauh negara atau wilayah itu telah mencapai sasaran yang ditentukan yaitu angka harapan hidup 85 tahun, pendidikan dasar bagi semua lapisan masyarakat (tanpa terkecuali), dan tingkat pengeluaran dan konsumsi yang telah 
mencapai standar hidup yang layak. Semakin dekat nilai IPM suatu wilayah terhadap angka 100, semakin dekat jalan yang harus ditempuh untuk mencapai sasaran itu. Karena hanya mencakup tiga komponen, maka IPM harus dilihat sebagai penyederhanaan dari realitas yang kompleks dari luasnya dimensi pembangunan manusia.

Rumus umum yang dipakai adalah sebagai berikut:

$$
\text { IPM }=\mathbf{1} / 3\left(X_{1}+X_{2}+X_{3}\right)
$$

di mana:

$\mathrm{X}_{1}=$ Indeks Harapan Hidup

$\mathrm{X}_{2}=$ Indeks Pendidikan

$\mathrm{X}_{3}=$ Indeks Standar Hidup Layak

\section{METODE PENELITIAN}

Data yang digunakan adalah data sekunder mengenai persentase rumah tangga dengan kondisi sanitaasi tidak layak, angka kematian ibu dan indeks pembangunan manusia di Sumatera Utara selama periode tahun 2014-2016. Adapun sumber data penelitian adalah diperoleh dari laporan statistik masing-masing kabupaten dan kota di Sumatera Utara.

\section{Teknik Analisis Data}

Analisis regresi yang digunakan adalah regresi panel. Data panel merupakan gabungan antara data cross section dan time series sehingga mampu menyediakan data lebih banyak dan menghasilkan degree of freedom yang lebih besar (Gujarati, 2004). Estimasi dalam model regresi panel dilakukan melalui 3 pendekatan yaitu CEM (Common Effect Model), FEM (Fixed Effect Model), dan REM (Random Effect Model).

1. CEM (Common Effect Model)

Model CEM melibatkan seluruh data digabungkan tanpa memperhatikan individu dan waktu. Persamaan model CEM dinyatakan dalam model sebagai berikut:

$$
Y_{i t}=\alpha+\beta^{\prime} X_{i t}+e_{i t}
$$

2. FEM (Fixed Effect Model)

Model FEM mengasumsikan bahwa intersep berbeda untuk tiap individu tetapi tetap mengasumsikan bahwa koefisien slope adalah konstan. Persamaan model FEM dinyatakan dalam model sebagai berikut:

$$
Y_{i t}=\alpha+\beta^{\prime} X_{i t}+e_{i t}
$$




\section{REM (Random Effect Model)}

Model REM mengestimasi data panel dimana variabel gangguan mungkin saling berhubungan (error terms) antar waktu dan antar individu. Persamaan REM dapat dinyatakan dalam persamaan sebagai berikut:

$$
\mathrm{Y}_{\mathrm{it}}=\alpha+\beta^{\prime} \mathrm{X}_{\mathrm{it}}+\mathrm{W}_{\mathrm{it}}
$$

Dengan nilai $W_{\text {it }}$

$$
\mathrm{W}_{\mathrm{it}}=\varepsilon_{\mathrm{it}}+\mu_{\mathrm{i}}
$$

\section{HASIL DAN PEMBAHASAN}

\section{Pemilihan Model Estimasi}

Pemilihan model estimasi perlu dilakukan dalam analisis regresi data panel. Metode yang digunakan dalam penelitian ini adalah uji chow dan uji hausman untuk menentukan pemilihan model yang paing tepat dalam mengestimasi data panel.

\section{Uji Chow}

Uji chow digunakan untuk mengetahui model terbaik antara Common Effect Model atau Fixed Effect Model yang akan dipilih untuk estimasi regresi data panel. Hasil uji chow dapat dijelaskan dalam tabel berikut:

Tabel 2. Hasil Uji Chow

\begin{tabular}{lrrr} 
Test cross-section fixed effects & & & \\
\hline \hline Effects Test & Statistic & d.f. & Prob. \\
\hline \hline Cross-section F & 85.182456 & $(32,64)$ & 0.0000 \\
Cross-section Chi-square & 373.710738 & 32 & 0.0000 \\
\hline \hline
\end{tabular}

Hasil uji chow menunjukkan bahwa nilai probabilitas Cross section $\mathrm{F}$ adalah sebesar 0.0000 dan Cross section Chi-square adalah 0.0000, sehingga nilai probabilitas kurang dari $\alpha$ (Q-value $\square 0.05$ ) yang artinya $\mathrm{H}_{0}$ ditolak. Hasil uji chow ini menunjukkan bahwa model terbaik yang digunakan dalam analisis regresi panel untuk penelitian ini adalah Fixed Effect Model.

\section{Uji Hausman}

Uji hausman digunakan untuk mengetahui model terbaik antara Fixed Effect Model atau Random Effect Model yang akan dipilih untuk estimasi regresi data panel. Hasil uji hasuman dapat dijelaskan dalam tabel berikut: 
Tabel 3. Hasil Uji Hausman

Correlated Random Effects - Hausman Test

\begin{tabular}{lrrr}
\hline \hline Test Summary & $\begin{array}{r}\text { Chi-Sq. } \\
\text { Statistic }\end{array}$ & Chi-Sq. d. f. & Prob. \\
\hline \hline Cross-section random & 18.912136 & 2 & 0.0001 \\
\hline \hline
\end{tabular}

Hasil uji hausman menunjukkan bahwa nilai probabilitas Cross section random adalah sebesar 0.0001 , sehingga nilai probabilitas kurang dari $\alpha$ (Qvalue $\square$ 0.05) yang artinya $\mathrm{H}_{0}$ ditolak. Hasil uji hausman ini menunjukkan bahwa model terbaik yang digunakan dalam analisis regresi panel untuk penelitian ini adalah Fixed Effect.

\section{Uji Statistik}

Uji statistik digunakan untuk melihat pengaruh parsial, simultan dan kontribusi dari masing-masing variabel bebas terhadap variabel terikatnya. Hasil uji statistik ditampilkan dalam tabel berikut ini.

Tabel 4. Hasil Uji Statistik

\begin{tabular}{|c|c|c|c|c|}
\hline \multicolumn{5}{|c|}{$\begin{array}{l}\text { Dependent Variable: IPM } \\
\text { Method: Panel Least Squares } \\
\text { Sample: } 20142016 \\
\text { Periods included: } 3 \\
\text { Cross-sections included: } 33 \\
\text { Total panel (balanced) observations: } 99\end{array}$} \\
\hline Variable & Coefficient & Std. Error & t-Statistic & Prob. \\
\hline $\begin{array}{c}\text { AKI } \\
\text { SANITASI } \\
\text { C }\end{array}$ & $\begin{array}{r}-0.191121 \\
-0.034049 \\
121.0537\end{array}$ & $\begin{array}{l}0.392170 \\
0.012521 \\
105.0020\end{array}$ & $\begin{array}{r}-0.487342 \\
-2.719316 \\
1.152870\end{array}$ & $\begin{array}{l}0.0277 \\
0.0084 \\
0.2533\end{array}$ \\
\hline \multicolumn{5}{|c|}{ Effects Specification } \\
\hline \multicolumn{5}{|c|}{ Cross-section fixed (dummy variables) } \\
\hline $\begin{array}{l}\text { R-squared } \\
\text { Adjusted R-squared } \\
\text { S.E. of regression } \\
\text { Sum squared resid } \\
\text { Log likelihood } \\
\text { F-statistic } \\
\text { Prob(F-statistic) }\end{array}$ & $\begin{array}{r}0.990175 \\
0.984955 \\
0.591755 \\
22.41116 \\
-66.93965 \\
189.6987 \\
0.000000\end{array}$ & \multicolumn{2}{|c|}{$\begin{array}{l}\text { Mean dependent var } \\
\text { S.D. dependent var } \\
\text { Akaike info criterion } \\
\text { Schwarz criterion } \\
\text { Hannan-Quinn criter. } \\
\text { Durbin-Watson stat }\end{array}$} & $\begin{array}{l}68.37495 \\
4.824417 \\
2.059387 \\
2.976854 \\
2.430595 \\
1.735148\end{array}$ \\
\hline
\end{tabular}




\section{Koefisien Determinasi ( $\left.\mathbf{R}^{2}\right)$}

Koefisien Determinasi atau $\mathrm{R}^{2}$ menunjukkan besarnya kontribusi dari persentase rumah tangga dengan kondisi sanitasi tidak layak dan angka kematian ibu terhadap indeks pembangunan manusia di Sumatera Utara. Dari tabel 4 dapat dilihat bahwa nilai R-squared sebesar 0.990175 yang artinya adalah kemampuan variabel persentase rumah tangga dengan kondisi sanitasi tidak layak dalam menjelaskan indeks pembangunan manusia di Sumatera Utara adalah sebesar $99.02 \%$ dan sisanya sebesar 0,98\% dijelaskan oleh variabel lain diluar model estimasi.

\section{Uji Simultan (Uji-F)}

Uji $F$ digunakan untuk menguji apakah semua variabel bebas yang digunakan memiliki pengaruh simultan terhadap variabel terikat. Hasil dari uji simultan (uji-F) diketahui nilai probabilitas F-statistik adalah sebesar 0.000 dan lebih kecil dari $\alpha=0.05$ sehingga $\mathrm{H}_{0}$ ditolak. Hasil tersebut menunjukkan bahwa variabel persentase rumah tangga dengan kondisi sanitasi tidak layak dan angka kematian ibu berpengaruh secara simultan terhadap variabel indeks pembangunan manusia di Sumatera Utara.

\section{Uji Parsial (Uji-t)}

Uji $\mathrm{t}$ digunakan untuk menguji apakah masing-masing variabel bebas memiliki pengaruh secara parsial dan signifikan terhadap variabel terikat. Hasil dari uji $t$ diketahui bahwa nilai koefisien untuk variabel persentase rumah tangga dengan kondisi sanitasi tidak layak adalah sebesar - 0.034049 dengan probabilitas sebesar 0.0084 , yang artinya variabel persentase rumah tangga dengan kondisi sanitasi tidak layak berpengaruh positif dan signifikan terhadap indeks pembangunan manusia di Sumatera Utara. Untuk variabel angka kematian ibu, koefisiennya sebesar -0.191121 dengan nilai probabilitas sebesar 0.0277 , yang artinya variabel angka kematian ibu berpengaruh negatif dan signifikan terhadap indeks pembangunan manusia di Sumatera Utara.

Hasil uji statistik menunjukkan bahwa variabel sanitasi yang tidak layak dan angka kematian ibu mempunyai pengaruh signifikan terhadap indeks pembangunan manusia di Sumatera Utara. Tanda negatif diartikan bahwa setiap terjadi kenaikan persentase rumah tangga dengan kondisi sanitasi yang tidak layak akan mengakibatkan penurunan indeks pembangunan manusia. Hal ini dikarenakan salah satu komponen IPM adalah angka

$$
\text { Q E J ournal | Vol.07 - N } 0.02 \text { July } 2018 \text { - } 124
$$


harapan hidup. Sanitasi yang tidak layak akan menurunkan kualitas hidup masyarakat sehingga angka harapan hidup akan semakin menurun karena berbagai penyakit akan mudah menyerang masyarakat.

Hal ini sejalan dengan penelitian yang dilakukan oleh Ferllando (2015). Dalam penelitiannya ditemukan hasil bahwa $45,7 \%$ balita mengalami diare pada 3 bulan terakhir. Faktor-faktor yang terbukti ada hubungan dengan kejadian diare antara lain personal hygiene $(\rho=0,000)$ dimana sebagian responden termasuk dalam kategori personal hygiene baik (53,3\%), kondisi lingkungan $(\rho=0,000)$ dimana sebagian besar responden termasuk dalam kategori kondisi lingkungan baik $(51,1 \%)$ dan penyediaan air bersih $(\rho=0,023)$ dimana sebagian besar responden termasuk dalam kategori tersedia $(81,9 \%)$. Sedangkan ketersediaan jamban $(\rho=0,504)$ terbukti tidak ada hubungan.

Sejalan dengan Ferllando, Ringkasan Kajian UNICEF Indonesia juga menemukan pentingnya sanitasi yang baik untuk kesehatan masyarakat. Sanitasi dan perilaku kebersihan yang buruk serta air minum yang tidak aman berkontribusi terhadap 88 persen kematian anak akibat diare di seluruh dunia. Bagi anak-anak yang bertahan hidup, seringnya menderita diare berkontribusi terhadap masalah gizi, sehingga menghalangi anakanak untuk dapat mencapai potensi maksimal mereka. Kondisi ini selanjutnya menimbulkan implikasi serius terhadap kualitas sumber daya manusia dan kemampuan produktif suatu bangsa di masa yang akan datang.

Rumah tangga dengan sanitasi yang tidak layak ini juga akan memberikan pengaruh buruk bagi kesehatan ibu yang sedang mengandung, karena sang ibu akan rentan terserang penyakit. Tingginya angka kematian ibu pada akhirnya akan memberikan pengaruh negatif terhadap indeks pembangunan manusia. Kenaikan angka kematian ibu akan menurunkan indeks pembangunan manusia.

\section{SIMPULAN DAN SARAN}

Adapun kesimpulan yang dapat diambil dari pembahasan tersebut adalah:

1. Rumah tangga dengan sanitasi yang tidak layak memberikan pengaruh negatif dan signifikan terhadap penurunan kualitas hidup masyarakat yang akhirnya akan berdampak pada penurunan IPM di Sumatera Utara. 
2. Angka kematian ibu yang tinggi akan menurunkan kualitas hidup masyarakat yang tercermin dalam semakin menurunnya IPM di Sumatera Utara.

Adapun saran yang dapat diambil dari pembahasan tersebut adalah:

1. Perlu adanya kesadaran masyarakat dalam memperhatikan kebersihan dan sanitasi yang layak dalam lingkungan. Hal ini dikarenakan akan berdampak kepada tingkat kesehatan masyarakat. Tingkat kesehatan yang tinggi akan mendorong indeks pembangunan manusia yang tinggi.

2. Diperlukan sosialisasi dari pemerintah daerah mengenai sanitasi yang layak dalam lingkungan masyarakat terutama untuk menjaga kesehatan ibu hamil. Karena kualitas penerus bangsa sangat ditentukan dari bayi dalam kandungan ibu.

\section{DAFTAR PUSTAKA}

Aristia, R. 2011. Faktor yang Mempengaruhi Kematian Ibu Hamil di Jawa Timur Dengan Menggunakan Geographically Weighted Poisson Regression. Surabaya: Institut Teknologi Sepuluh Nopember.

Darwin, Eryati. 2014. Etika Profesi Kesehatan. Yogyakarta: Deepublish.

Ferllando, Herry Tomy dan Supriyono Asfawi. 2015. Hubungan Antara Sanitasi Lingkungan dan Personal Hygiene Ibu dengan Kejadian Diare pada Balita di Wilayah Kerja Puskesmas Mangkang. Jurnal Kesehatan Volume 14, Nomor 2.

Gujarati. 2004. Basic Econometrics. New York: Mc Gwra Hill, Inc.Pertiwi, L. D. 2012. Spatial Durbin Model untuk Mengidentifikasi Faktor-Faktor yang Mempengaruhi Kematian Ibu di Jawa Timur. Surabaya: Institut Teknologi Sepuluh Nopember.

Ryadi, Alexander Lucas Slamet. 2016. Ilmu Kesehatan Masyarakat. Yoygakarta: Andi.

Sari, Afsah Novita. 2016. Analisis Jalur Faktor-Faktor yang Mempengaruhi Angka Kematian Ibu di Jawa Timur. Jurnal Matematika dan Pendidikan Matematika Vol. I No. 2. 
Sidhi, Alifia Nugrahani, Mursid Raharjo dan Nikie Astorina Yunita Dewanti. 2016. Hubungan Kualitas Sanitasi Lingkungan dan Bakteriologis Air Bersih terhadap Kejadian Diare pada Balita di Wilayah Kerja Puskesmas Adiwerna Kabupaten Tegal. Jurnal Kesehatan Masyarakat Volume 4, Nomor 3.

UNDP. 1995. Human Development Report. New York: Oxford University Press.

UNICEF Indonesia. 2012. Air Bersih, Sanitasi dan Kebersihan. Ringkasan Kajian.

World Health Organization. 2009. Global health risks: Mortality and burden of disease attributable to selected major risks. Geneva: WHO Press. 